\title{
Preparation of New Photocatalyst for Removal of Alizarin Red-S from Aqueous Solution
}

\author{
Hadi Roopaei ${ }^{1}$, Ahmad Reza Zohdi ${ }^{1}$, Zahra Abbasi ${ }^{2 *}$ and Mehrnoosh Bazrafkan ${ }^{3}$ \\ 'Department of Mathematics, College of Mathematic, Marvdasht Branch, Islamic Azad University, \\ Marvdasht, Iran; Ahmadrezazohdi@yahoo.com, H.roopaei@gmail.com \\ 2Department of Chemistry, College of Chemistry Sciences, Marvdasht Branch, \\ Islamic Azad University, Marvdasht, Iran; Zahra.Abbasi886@gmail.com \\ ${ }^{3}$ Department of Computer Engineering, College of Computer, Marvdasht Branch, \\ Islamic Azad University, Marvdasht, Iran; Mehrnoosh.bazrafkan@gmail.com
}

\begin{abstract}
In this paper, $\alpha-\mathrm{Fe}_{2} \mathrm{O}_{3} / \mathrm{NiS}$ has been synthesized as a Photocatalyst for Removal of Alizarin red-S from Aqueous Solution. The as-prepared sample were characterized by X-ray diffraction (XRD), scanning electron microscopy (SEM), transmission electron microscopy (TEM) and Fourier transform infrared spectra (FTIR). Then photocatalytic degradation was carried out in the presence of the $\alpha-\mathrm{Fe}_{2} \mathrm{O}_{3} / \mathrm{NiS}$ on Alizarin red-S. The effect of catalyst dose, $\mathrm{pH}$ and initial dye concentration on the degradation process has been assessed. Different concentrations of $\alpha-\mathrm{Fe}_{2} \mathrm{O}_{3} / \mathrm{NiS}$ photocatalyst $(0.25,0.50,0.75,1.0,1.25$, $1.5,1.75$ and $2 \mathrm{~g} / \mathrm{L})$, different $\mathrm{pH}$ values $(1-10)$ and different concentrations of dye (10-100 ppm) were employed for the present study.
\end{abstract}

Keywords: Photocatalytic, Alizarin Red-S, Magnetic Nanoparticle

\section{Introduction}

Polluted waste water plays significant role in environmental pollution. Industrial effluents contain different chemicals especially synthetic dyes which are carcinogenic in nature ${ }^{1-3}$. Some dyes decompose aerobically and anaerobically resulting in the formation of carcinogenic compounds ${ }^{4,5}$. In addition the coloured pollutants decrease light penetration \& prevent photosynthesis ${ }^{6}$. Alizarin red-S dye is one of them which produces 'red and' purple coloured solution depending on $\mathrm{pH}$ of water. Many conventional methods for the removal of dying effluents from aqueous solutions can be divided into three classes; physical biological and chemical treatments. Alizarin red-S is used in large quantities in dying industries \& produces many environment problems. To find an appropriate \& cost effective adsorbent is an important consideration for designing a suitable adsorption method to minimize water pollution ${ }^{7-9}$.
Currently, many semiconductors have been applied in heterogeneous photocatalysis such as $\mathrm{CdS}, \mathrm{SnO}_{2}, \mathrm{WO}_{3}$, $\mathrm{TiO}_{2}, \mathrm{ZrTiO}_{4}$, and $\mathrm{ZnO}^{9-12}$. These advantages include high efficiency, strong oxidation power, low cost, environmental benignity, and excellent chemical and photo-chemical stability. Hematite $\left(\alpha-\mathrm{Fe}_{2} \mathrm{O}_{3}\right)$ is one of the most stable iron oxides with n-type semiconducting properties. Because of its low cost, simple production, environmental friendliness, and excellent chemical stability, $\alpha-\mathrm{Fe}_{2} \mathrm{O}_{3}$ has been intensively investigated in a variety of applications such as catalysts, pigments, water treatment, magnetic materials, sensors, and lithium ion batteries. With a low band gap of $2.2 \mathrm{eV}, \alpha-\mathrm{Fe}_{2} \mathrm{O}_{3}$ absorbs most of the visible light, becoming a promising visible-light-driven photocatalyst In contrast with other semiconductors (i.e., $\mathrm{WO}_{3}, \mathrm{ZnO}, \mathrm{ZnS}, \mathrm{Fe}_{2} \mathrm{O}_{3}$, $\mathrm{CdS}$, and $\mathrm{SrTiO}_{3}$ ), $\mathrm{TiO}_{2}$ is widely used in environmental applications because of its physical and chemical stability, lower cost, non-toxicity and resistance to corrosion.

*Author for correspondence 
In this paper, photocatalytic $\alpha-\mathrm{Fe}_{2} \mathrm{O}_{3} / \mathrm{NiS}$ has been synthesized successfully by hydrothermal method. The as-prepared sample were characterized by X-ray diffraction (XRD), scanning electron microscopy (SEM), transmission electron microscopy (TEM) and Fourier transform infrared spectra (FTIR). The photocatalytic activities of the $\alpha-\mathrm{Fe}_{2} \mathrm{O}_{3} / \mathrm{NiS}$ were evaluated by the photocatalytic degradation of Alizarin red-S.

\section{Experimental}

\subsection{Materials}

Alizarin red S (98\%) was purchased from Loba Chem Co. Ferric chloride $\left(\mathrm{FeCl}_{3} \cdot 6 \mathrm{H}_{2} \mathrm{O}\right)$ and $\mathrm{NiCl}_{2} \cdot 6 \mathrm{H}_{2} \mathrm{O}$, were obtained from Aldrich. All other chemicals were used as received without further purification. Freeze dryer FD-10 (Pishtaz Engineering Co, Iran). IR spectra were recorded on a Frontier Fourier transform infrared (FTIR) (Perkin Elmer) spectrometer using a $\mathrm{KBr}$ disk. dye concentration were determined in the filtrate using (Shimadzu UV-1601 $\mathrm{UV} / \mathrm{Vis}$ spectrophotometer). $\mathrm{pH}$ adjustments were made with digital $\mathrm{pH}$-meter (Sartorius, Model PP-20) using $\mathrm{HCl}\left(0.1 \mathrm{~mol} \mathrm{~L}^{-1}\right)$ and $\mathrm{NaOH}\left(0.1 \mathrm{~mol} \mathrm{~L}^{-1}\right)$.

\subsection{Synthesis of $\alpha-\mathrm{Fe}_{2} \mathrm{O}_{3}$}

The $\alpha-\mathrm{Fe}_{2} \mathrm{O}_{3}$ were pre-synthesized by a hydrothermal method. In a typical process, $\mathrm{FeCl}_{3}(0.01 \mathrm{~mol})$ was dissolved in deionized water $(30 \mathrm{~mL})$. The solution was then mixed with $15 \mathrm{~mL}$ of $\mathrm{NaOH}$ aqueous solution $(2 \mathrm{M})$. The obtained precipitation was washed by deionized water for 8 times. After washing, the precipitation was dispersed in $50 \mathrm{~mL}$ of $\mathrm{NaOH}$ aqueous solution $(2 \mathrm{M})$ under vigorous magnetic stirring for $1 \mathrm{~h}$. Then the suspension was transferred into a $100 \mathrm{~mL}$ autoclave Teflon vessel and hydrothermally treated at $160^{\circ} \mathrm{C}$ for $20 \mathrm{~h}$. After that, the autoclave was cooled down to room temperature naturally. The resulting sample was washed with deionized water and ethanol and separated by centrifugation each for three times. The final product of the $\alpha-\mathrm{Fe}_{2} \mathrm{O}_{3}$ were dried at $60^{\circ} \mathrm{C}$ and heat treated at $400^{\circ} \mathrm{C}$ for $3 \mathrm{~h}^{13}$.

\subsection{Synthesis of $\alpha-\mathrm{Fe}_{2} \mathrm{O}_{3} / \mathrm{NiS}$}

In a typical synthetic process, $\alpha-\mathrm{Fe}_{2} \mathrm{O}_{3}(0.02 \mathrm{~g})$ were welldispersed in deionized water $(30 \mathrm{~mL})$ under magnetic stirring and then $1.0 \mathrm{mmol}$ of $\mathrm{NiCl}_{2} \cdot 6 \mathrm{H}_{2} \mathrm{O}$ solution (3 $\mathrm{mL}$ ) was introduced into the mixture. Subsequently, the resulting solution was irradiated by $40 \mathrm{kHz}$ ultrasonic waves at $80 \%$ output power in the air for $30 \mathrm{~min}$. During the reaction, temperature was controlled at about $45^{\circ} \mathrm{C}$. The precipitates were collected and washed with distilled water and absolute ethanol several times and then dried in a vacuum at $200{ }^{\circ} \mathrm{C}$ overnight for $10 \mathrm{~h}$.

\subsection{Adsorption Experiments}

The adsorption studies were carried out at $25 \pm 1^{\circ} \mathrm{C} \cdot \mathrm{pH}$ of the solution was adjusted with $0.1 \mathrm{~N} \mathrm{HCl}$. A known amount of adsorbent was added to sample and allowed sufficient time for adsorption equilibrium. Then the mixture were filtered and the remaining dye concentration were determined in the filtrate using (Shimadzu UV-1601 $\mathrm{UV} / \mathrm{vis}$ spectrophotometer) at $\lambda_{\max }=425 \mathrm{~nm}$. The effect of various parameters on the rate of adsorption process were observed by contact time, $t$, initial concentration of dye $\mathrm{C}_{\mathrm{o}}$, initial $\mathrm{pH}$ of solution, and temperature. The solution volume $(\mathrm{V})$ was kept constant $50 \mathrm{~mL}$ ). The dye adsorption (\%) at any instant of time was determined by the following equation:

Dye adsorption $(\%)=\left(\mathrm{C}_{\mathrm{o}}-\mathrm{C}_{\mathrm{e}}\right) \times 100 / \mathrm{C}_{\mathrm{o}}$

Where $\mathrm{C}_{\mathrm{o}}$ is the initial concentration and $\mathrm{C}_{\mathrm{e}}$ is the concentration of the dye at equilibrium. To increase the accuracy of the data, each experiment was repeated three times and average values were used to draw the graphs.

\section{Results and Discussion}

Surface characteristics of the samples SEM provides information on the micro-surface structures, as shown in Figure 1. Very uniform particles with a favorable morphology could be observed for the $\alpha-\mathrm{Fe}_{2} \mathrm{O}_{3} / \mathrm{NiS}$, as seen from the high magnification image in Figure 1(a), which suggests that a core material of pure $\alpha-\mathrm{Fe}_{2} \mathrm{O}_{3}$ was uniformly enclosed or overlapped with nanoscale NiS particles via the hydrothermal reaction. For obtaining detailed and high magnification images of the surface nanostructures and particle sizes of the $\alpha-\mathrm{Fe}_{2} \mathrm{O}_{3} / \mathrm{NiS}$, TEM analysis was performed, as shown in Figure 2. From the high magnification TEM images of Figure 2(a), it is observed that the $\alpha-\mathrm{Fe}_{2} \mathrm{O}_{3}$ / $\mathrm{NiS}$ particles exhibit uniform size distribution, and the $\alpha-\mathrm{Fe}_{2} \mathrm{O}_{3}$ particles are cube-shaped with the size of $\sim 20 \mathrm{~nm}$.

The Fourier Transform Infrared (FTIR) spectrum of synthesized $\alpha-\mathrm{Fe}_{2} \mathrm{O}_{3} / \mathrm{NiS}$ is shown in Figure 3. The presence of some functional groups on the surface of 

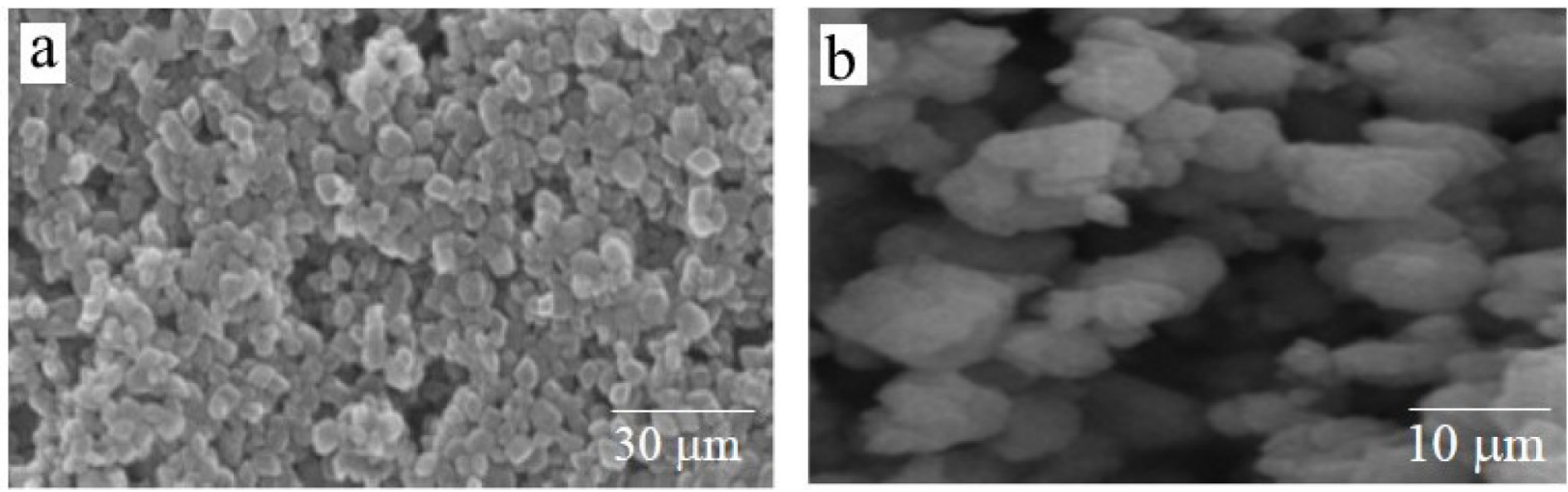

Figure 1. SEM micrographs of $\alpha-\mathrm{Fe}_{2} \mathrm{O}_{3}(\mathrm{a}), \alpha-\mathrm{Fe}_{2} \mathrm{O}_{3} / \mathrm{NiS}(\mathrm{b})$.
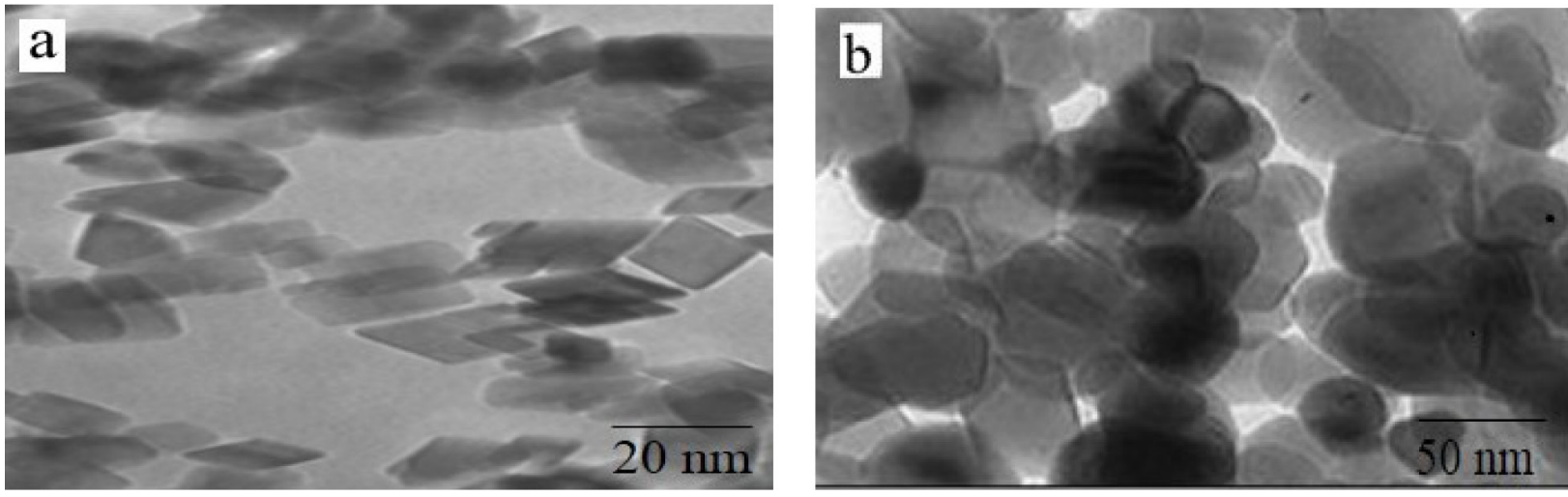

Figure 2. TEM of $\alpha-\mathrm{Fe}_{2} \mathrm{O}_{3}(\mathrm{a}), \alpha-\mathrm{Fe}_{2} \mathrm{O}_{3} / \mathrm{NiS}(\mathrm{b})$.

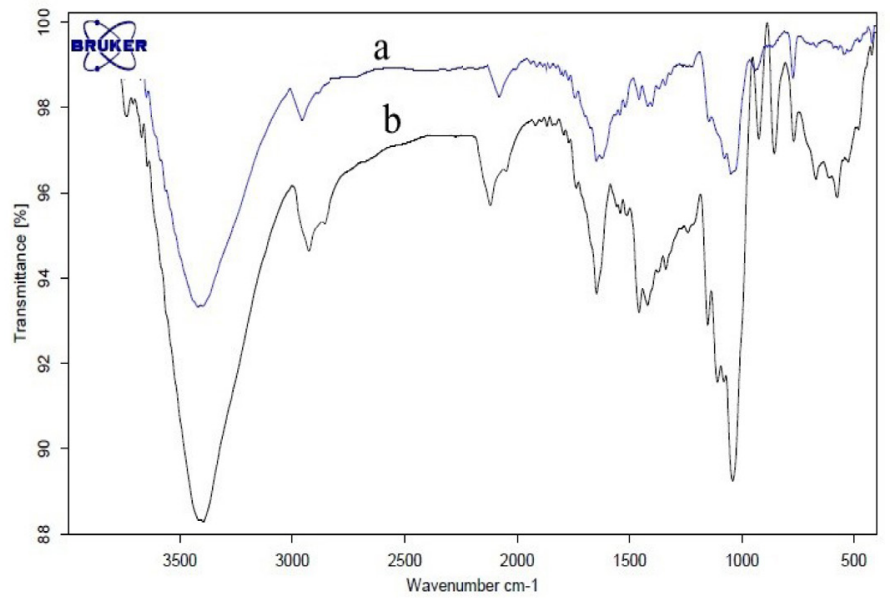

Figure 3. FT-IR spectra of $\alpha-\mathrm{Fe}_{2} \mathrm{O}_{3}(\mathrm{a}), \alpha-\mathrm{Fe}_{2} \mathrm{O}_{3} / \mathrm{NiS}(\mathrm{b})$.

the particles is obvious. The most significant peaks appeared at $1310 \mathrm{~cm}^{-1}$ and $1615 \mathrm{~cm}^{-1}$ and are related to the stretching mode of the carboxylic group ${ }^{8}$. There are other peaks at $1050 \mathrm{~cm}^{-1}$ and $1685 \mathrm{~cm}^{-1}$ that are related to $\mathrm{C}-\mathrm{O}$ and $\mathrm{C}=\mathrm{O}$ respectively in the carboxylic group. Finally, the broad stretched peak at $3460 \mathrm{~cm}^{-1}$ represents $\mathrm{OH}$. The FTIR result clearly suggests that $\alpha-\mathrm{Fe}_{2} \mathrm{O}_{3} / \mathrm{NiS}$ synthesized in this method are capped by some carboxylic groups which in previous studies were attributed to citrate. 
The X-ray diffraction (XRD) pattern of synthesized $\alpha-\mathrm{Fe}_{2} \mathrm{O}_{3} / \mathrm{NiS}$ (Figure 4) indicates that magnetite particles have a highly crystalline cubic spinel structure. The diffraction peaks at $31.2,35.4,42.9,54.1,57.4,63.1$ and $67.4^{\circ}$ responded to cubic $\mathrm{Fe}_{2} \mathrm{O}_{3}$ lattice, respectively. The cubic spinel structure of $\mathrm{Fe}_{2} \mathrm{O}_{3}$ is proven by comparing the XRD pattern with others reported in literature ${ }^{10,13}$.

The efficiencies of photocatalytic processes strongly depend upon the $\mathrm{pH}$ of the reaction solution. The removal of Alizarin red-S dye was maximum at $\mathrm{pH} 5.0$ was reported $88.3 \%$ and it is increases from 4 to 6 from 74.2 to $89.3 \%$ and decreases from $\mathrm{pH} 6$ to 10 There is very slight difference in the percentage removal at 4 to 6 (Fig.5). Therefore the $\mathrm{pH}$ was fixed at 5.0 for the further experiment (Shimadzu UV-1601 UV/vis spectrophotometer).
Initial dye concentration was one of the effective factors on adsorption efficiency. The percentage of Alizarin Red S adsorption was studied as a function initial dye concentration of in the range of 10-100 ppm. The results obtained are present in Figure 6. The percentage adsorption increases with increase in initial concentration of the dye for $\alpha-\mathrm{Fe}_{2} \mathrm{O}_{3} /$ NiS. It was observed that adsorption yield increased with increase in initial concentration of the dye. Minimum adsorption was $38 \%$ for $10 \mathrm{ppm}$ concentration to maximum adsorption value $91 \%$ for $100 \mathrm{ppm}$ concentration of dye solution. This may be due to available active sites and increase in the driving force of the concentration gradient, as an increase in the high initial concentration of the dye.

In slurry photocatalytic processes, catalyst dosage is an important parameter that has been extensively studied.

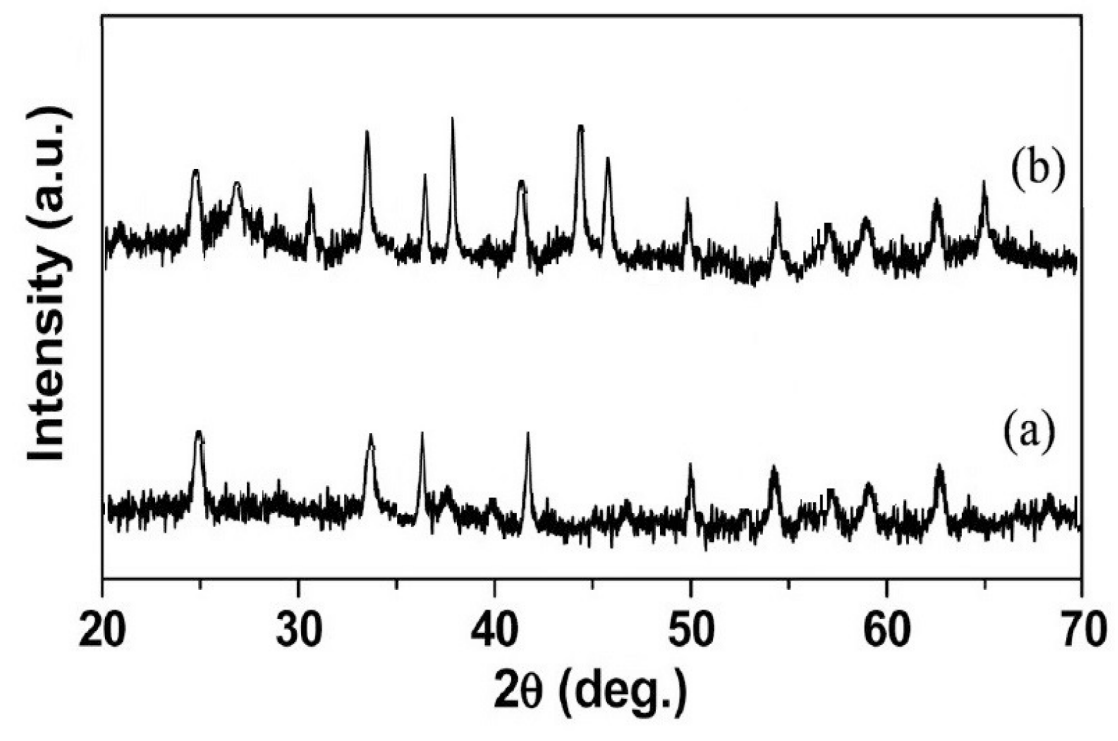

Figure 4. $\mathrm{XRD}$ of $\alpha-\mathrm{Fe}_{2} \mathrm{O}_{3}(\mathrm{a}), \alpha-\mathrm{Fe}_{2} \mathrm{O}_{3} / \mathrm{NiS}(\mathrm{b})$.

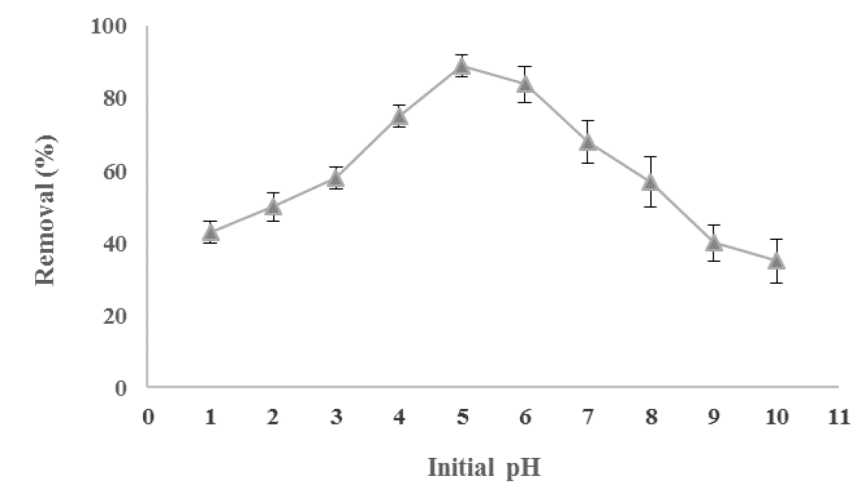

Figure 5. Effect of $\mathrm{pH}$. 


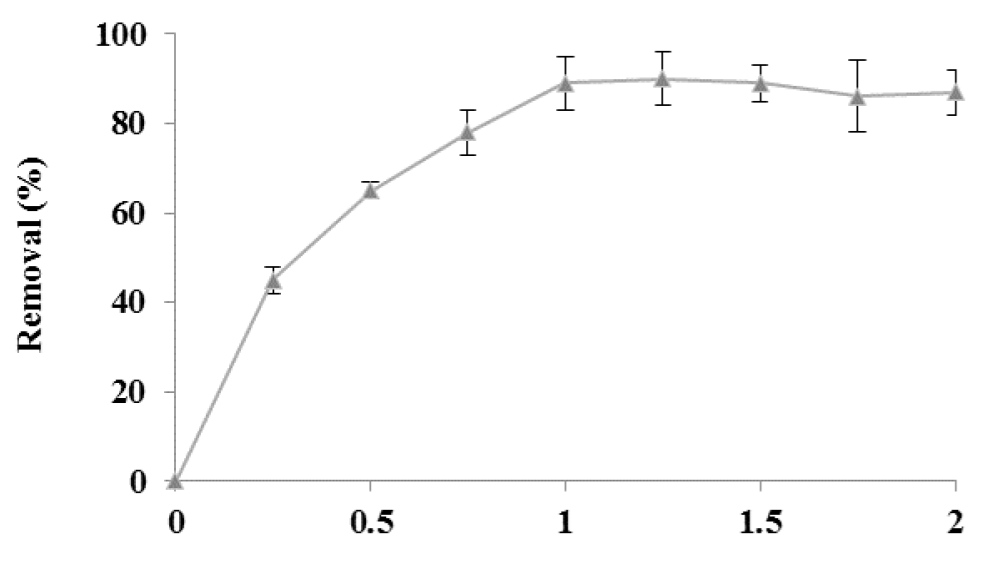

Adsorbent Dose (g)

Figure 6. Effect of adsorbent dose.

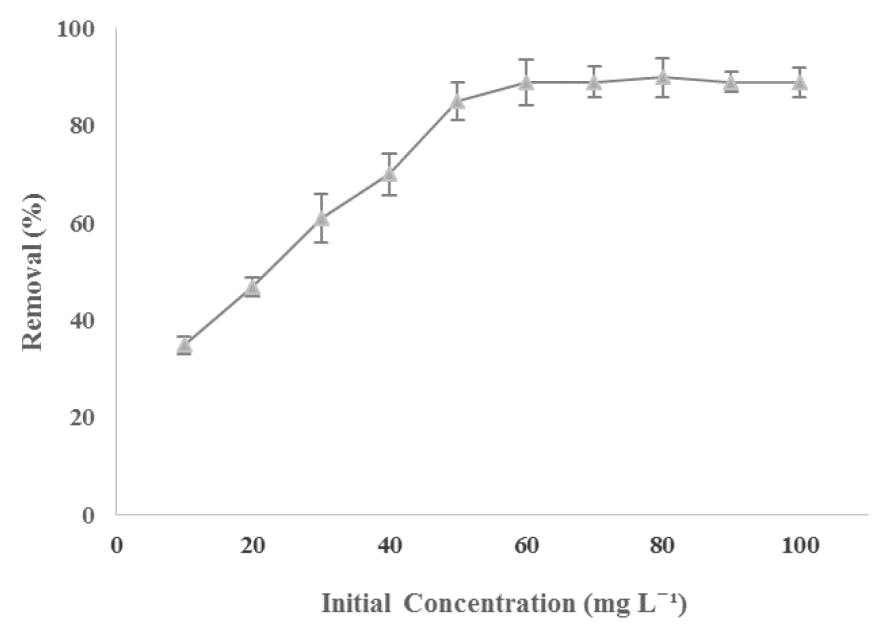

Figure 7. Effect of initial concentration.

The rate of photocatalytic reaction is strongly influenced by concentration of the photocatalyst. Heterogeneous photocatalytic reactions are known to show proportional increase in photodegradation with catalyst loading. Generally, in any given photocatalytic application, the optimum catalyst concentration must be determined, in order to avoid excess catalyst. The results indicate that the percentage removal of Alizarin red-S increases as the adsorbent dose increases (Figure 7). Due to the increase in photocatalyst dosage the percentage of dye removal also increases.

\section{Conclusion}

From the present study, we $\alpha-\mathrm{Fe}_{2} \mathrm{O}_{3} / \mathrm{NiS}$ has been synthesized is a good Photocatalyst for the removal of the dyes from aqueous media. Optimum conditions for the removal of Alizarin Red S with $\alpha-\mathrm{Fe}_{2} \mathrm{O}_{3} / \mathrm{NiS}$ are: $1 \mathrm{~g}$ of 
adsorbent, dye concentration $50 \mathrm{ppm}$, at $25^{\circ} \mathrm{C}$ and at $\mathrm{pH}$ 5.0 .

\section{References}

1. S. Parsons. (2004). Advanced Oxidation Processes for Water and Wastewater, IWA Publishing, London, UK.

2. Y. Li, S. Sun, M. Ma, Y. Ouyang and W. Yan. Kinetic study and model of the photocatalytic degradation of rhodamine $\mathrm{B}(\mathrm{RhB})$ by a TiO2-coated activated carbon catalyst: effects of initial $\mathrm{RhB}$ content, light intensity and $\mathrm{TiO} 2$ content in the catalyst. Chemical Engineering Journal. 2008;142, 147155.

3. M.N. Chong, B. Jin, C.W.K. Chow and C. Saint. recent developments in photocatalytic water treatment technology: a review. Water Research. 2010;44,2997-3027.

4. C. M. So, M.Y. Cheng, J.C. Yu and P.K. Wong. Degradation of azo dye Procion Red MX-5B by photocatalytic oxidation. Chemosphere. 2002;46,905-912.

5. N. Daneshvar, D. Salari and A.R. Khataee. Photocatalytic degradation of azo dye Acid Red 14 in water: investigation of the effect of operational parameters. Journal of Photochemistry and Photobiology A: Chemistry. 2003;157,111-116.

6. M. H. Habibi and N. Talebian. Photocatalytic degradation of an azo dye X6G in water: a comparative study using nanostructured indium tin oxide and titanium oxide thin films, Dyes and Pigments. 2007;73,186-194.

7. M.A. Rauf and S.S. Ashraf. (2009). Application of Advanced Oxidation Processes (AOP) to dye degradation-an over- view, in: Arnold R. Lang (Ed.), Dyes and Pigments: New Research, Nova Science Publishers, Inc.

8. L. Zhang, Y. He, Y. Wu and T. Wu. Photocatalytic degradation of $\mathrm{RhB}$ over $\mathrm{MgFe} 2 \mathrm{O} 4 / \mathrm{TiO} 2$ composite materials. Materials Science and Engineering: B. 2011;176(18), $1497-$ 1504.

9. Y. Yan, H. Sun, P. Yao, S. Z. Kang and J. Mu. Effect of multiwalled carbon nanotubes loaded with Ag nanoparticles on the photocatalytic degradation of rhodamine B under visible light irradiation. Applied Surface Science. 2011;257(8), 3620-3626.

10. J. F. Guo, B. Ma, A. Yin, K. Fan and W. L. Dai. Photodegradation of rhodamine $\mathrm{B}$ and 4-chlorophenol using plasmonic photocatalyst of $\mathrm{Ag}-\mathrm{AgI} / \mathrm{Fe} 3 \mathrm{O} 4 . \mathrm{SiO} 2$ magnetic nanoparticle under visible light irradiation. Applied Catalysis B: Environmental. 2011;101(3-4),580586.

11. J. Xia, A. Wang, X. Liu and Z. Su. Preparation and characterization of bifunctional, $\mathrm{Fe} 3 \mathrm{O} 4 / \mathrm{ZnO}$ nanocomposites and their use as photocatalysts. Applied Surface Science, 2011;257(23), 9724-9732.

12. M. M. Curri, R. Comparelli, P.D. Cozzoli, G. Mascolo and A. Agostiano. Colloidal oxide nanoparticles for the photocatalytic degradation of organic dye. Materials Science and Engineering: C. 2003;23(1-2), 285-289.

13. X. Liu, Q. Hu, X. Zhang, Z. Fang and Q. Wang. Generalized and Facile Synthesis of Fe3O4/MS (M) Zn, Cd, Hg, Pb, Co, and Ni) Nanocomposites. J. Phys. Chem. C. 2008;112, 12728-12735. 